\title{
New earthworm species from NIBR's Jeju-do biosphere compared to historical and new Japanese types (Oligochaeta: Megadrilacea: Megascolecidae)
}

\author{
Robert J. Blakemore* \\ National Institute of Biological Resources (NIBR), Incheon 404-708, Korea \\ *Correspondent: rob.blakemore@gmail.com
}

\begin{abstract}
Amynthas tralfamadore sp. nov. is described from the Mt Halla, Jeju Island biosphere exhibition housed at NIBR Incheon. This species' taxonomy is problematical since it is similar to Amynthas masatakae (Beddard, 1892) from Japan, itself previously reported from Korea and at one time associated with Amynthas campestris (Goto \& Hatai, 1898) and A. parvicystis (Goto \& Hatai, 1899), all three variously implicated in prior $A$. robustus (Perrier, 1872) along with Amynthas aspergillum (Perrier, 1872). Based on reinspection of the London lectotype of $A$. masatakae-here designated and sketched for the first time-the current solution is for maintenance of all five taxa separately. A closely-related Japanese species-Metaphire ryunome sp. nov.-is comparable to Korean Metaphire reisuiensis (Kobayashi, 1938) comb. nov. Another specimen was identified as Amynthas micronarius (Goto \& Hatai, 1898), a new record for Korea. It matches the newly-designated neotype (Tokyo NMST An446) and an annotated synonymy is provided; however, erstwhile synonyms, Amynthas shimaensis (Goto \& Hatai, 1899) and A. yamizoyamensis (Ohfuchi, 1935) combs. novae, are briefly redescribed and provisionally restored to the Japanese list. mtDNA COI-5P barcode analyses support species identifications.
\end{abstract}

Keywords: Asia, biodiversity, endemic, exotic, neotypes, parthenogenetic, synonyms

\section{INTRODUCTION}

The NIBR museum and display facility in Incheon houses a climate-controlled (subtropical) "Gotjawal" forest conservatory of the mid-slope of volcanic Mt Halla, Jeju Island ecosystem. A brief check of moist 'hot spots' here unearthed two worms.

One specimen was Amynthas tralfamadore sp. nov., and its similarity to taxa reported from Japan and Korea, viz. A. robustus (Perrier, 1872) and its erstwhile synonyms A. masatakae (Beddard, 1892) and A. parvicystis (Goto \& Hatai, 1899), require that historical accounts of these are first clarified with reference to types and/or original descriptions before this, or any similar "new" taxa, are described.

A second specimen was Amynthas micronarius (Goto \& Hatai, 1898), one of the better described of these authors' numerous species names (cf. Blakemore, 2012a). Nevertheless, Michaelsen (1900: 316) thought that this taxon, along with eleven other of Goto \& Hatai's 28 names, may be the same as Japanese Pheretima divergens (Michaelsen, 1892) (=Amynthas corticis Kinberg, 1867) whereas Easton (1981) and Blakemore (2003) main- tained it. Being a patently parthenogenetic taxon (the original material lacked spermathecal diverticula) has allowed various stages of degradation to be afforded species names by subsequent workers unfamiliar with these events. According to the ICZN (1999) code, such morphs do not warrant separate specific identity and should be combined with the earliest valid name. In order to identify the NIBR specimen it was necessary to clarify the original state and status of this taxon and, since no types are known to exist, to designate a neotype from material probably identified by the original co-author, Dr S. Hatai. The neotype is compared to synonyms and incidental material from Japan and, now, from Korea.

\section{Materials And Methods}

Specimens were collected from moist microhabitats in the biosphere one afternoon. Types of Perichaeta masatakae obtained from the Natural History Museum, London (courtesy of Invertebrates curator Emma Sherlock) are redescribed and compared to the new Korean specimen and to others from Japan.

For Amynthas micronarius, the neotype was contained 
within an historical 1920-30s collection removed from the Saito Ho-on Kai Museum, Sendai (where author Dr Shinkishi Hatai worked as director in 1930s) by Dr M. Izukai and Kotaro Ishizuka many years ago in "1981 (Showa 61) [sic]" (see Blakemore, 2012b). These specimens are now deposited in the National Museum of Nature $\&$ Science in Tokyo (hereafter NMST) under care of senior curator Dr Toshiaki Kuramochi. Other historical Goto \& Hatai type material from the University of Tokyo Zoological Museum (UMUTZ) was also loaned out but their importance apparently not recognized by Mr Ishizuka (vide infra and see Blakemore \& Ueshima, 2011).

Small tissue samples were taken (as per Blakemore, 2010a; Blakemore et al. 2010) for DNA extraction and cytochrome-c oxidase subunit 1 (COI) barcoding under the iBOL (the International Barcode of Life program conducted by Drs Paul Hebert, Nataly Ivanova and Paul Prosser at Guelph University, Canada using methodology of Bhadury et al., 2006), but results thus far have been unsuccessful on older, formalin preserved material.

However, COI barcode data from the more recent material (some courtesy of TaeSeo Park curator of "marine" Annelida, NIBR) are appended. Preliminary nucleotide analysis used BLAST programs [http://www.blast. ncbi.nlm.nih.gov/BLAST.cgi].

Taxonomic determinations follow the methodology and classifications in Blakemore (2000; 2010b). Abbreviations are: GMs-genital markings, lhs-left hand side and rhsright hand side, syns.-synonyms; ?-indicates some uncertainty.

\section{TAXonomic Results}

Annelida Lamarck, 1802: Oligochaeta Grube, 1850: Megadrilacea Benham, 1890: Megascolecidae Rosa, 1891 sensu Blakemore, 2000

Genus Amynthas Kinberg, 1867

\section{Amynthas masatakae (Beddard, 1892)}

[Fig. 1]

Perichaeta masatakae Beddard, 1892: 761. Published December, 1892 according to Michaelsen (1900). From “Japan”. Syntypes listed by Sims \& Easton (1992: 181) as BMNH: 1904:10:5:91/92 but actually 1904:10.5. 912-913 (pers. obs.). Beddard, 1895: 414.

?[Perichaeta campestris Goto \& Hatai, 1898: 67, textfig. From Kamakura, Japan. No types. Non Ph. campestris Lee, 1952 (=A. corticis). Most often synonymized under A. robustus proper (see Fig. 2), but here provisionally retained separately].

?Perichaeta parvicystis Goto \& Hatai, 1899: 18, figs. 8, 8a, 8b. From Uwajima (Ehime-ken, Shikoku) and Oarai (Ibaraki-ken, Honshu). No types. (See Fig. 3).
Amyntas masatakae: Beddard, 1900: 632 (syn. campestris).

Pheretima masatakae: Michaelsen, 1900: 282; Kobayashi, 1937: 337, fig. 2, 1938: 137 (?part.); Ohfuchi, 1938: 62, figs. 6-7.

Pheretima masatake (sic lapsus): Ohfuchi, 1956: 132, fig. 11 (?part. cf. A. robustus).

Amynthas mastakae (sic lapsus): Sims \& Easton 1972: 181, 234, 244.

Amynthas masatakae: Chuang \& Chen, 2002: 73, fig. 1.

Note. Easton (1981: 56) had "mastakae" (sic lapsus) in synonymy of A. robustus (Perrier, 1872) as per Gates (1939: 473), but this, like many of Gates' "synonymies", not necessarily the original species, for some reason (or none), just a later citation requiring that all these references are again re-checked from original sources-see Remarks below. Following Easton, Blakemore (2003: 7) had it in A. robustus too with syns.: masatakae, campestris, ?zavatarii, ornata, ?sheni, lauta, corrugata.

Material examined. BMNH: 1904:10.5.912-913, labeled "SYNTYPES 1904: 10.5.912-3 Perichaeta masatakae Beddard 1892 Coll. by Mr Masatake Rokugo" (lapsus for Masataka Rokugo-cf. his Perichaeta rokugo). Two mature specimens, both previously dissected and rather macerated in mid-body, plus a spermatheca (91hs) in a small vial in the jar(Fig. 1). In order to enhance the stability of nomenclature, under ICZN (1999: Art. 72; et Decl. 44), the specimen newly figured (912) I hereby designate the LECTOTYPE since it was the basis of Beddard's description (being donor of the removed spermatheca), it is $115 \mathrm{~mm}$ long but missing its posterior tip. Specimen (913) in the same jar, that had had its $18 \mathrm{lhs}$ prostate duct and GM glands removed (missing), thus becomes the PARALECTOTYPE.

Japan: Lake Biwa Museum(LBM 1380000087), from Hikone (collected 18.VI.2009) four specimens that I initially mislabeled "Metaphire spex" or as A. robustus (as it was then known in 2010); NIBR (IV0000251098), from Nogeyama, Yokohama, collected 4.VI.2012 by RJB and T.J. Tansy, mature specimen found stranded and distressed on road in early evening after rain (dissected and figured, Fig. 1).

Diagnosis (from Beddard, pers. obs. and good references in synonymy above). Colour dark brown. Length $105-150+\mathrm{mm}$ by 4.0-7.5 mm wide; body cylindrical caudally tapering, segments 88-138. Lectotype and paralectotype $110+$ and $130 \mathrm{~mm}$, respectively the latter with 88 segments and a tapering tail (cf. $125 \mathrm{~mm}$ with $90 \mathrm{seg}$ ments by Beddard for the same specimen), Nogeyama specimen $150+\mathrm{mm}$, Ohfuchi (1938) has size up to 189 mm with 125 segments. Prostomium open epilobous. First dorsal pore at $11 / 12$ or $12 / 13$ in Ohfuchi's specimens. Setae ca. 30-52 (40-50 in lectotype), (cf. 20-64 by 

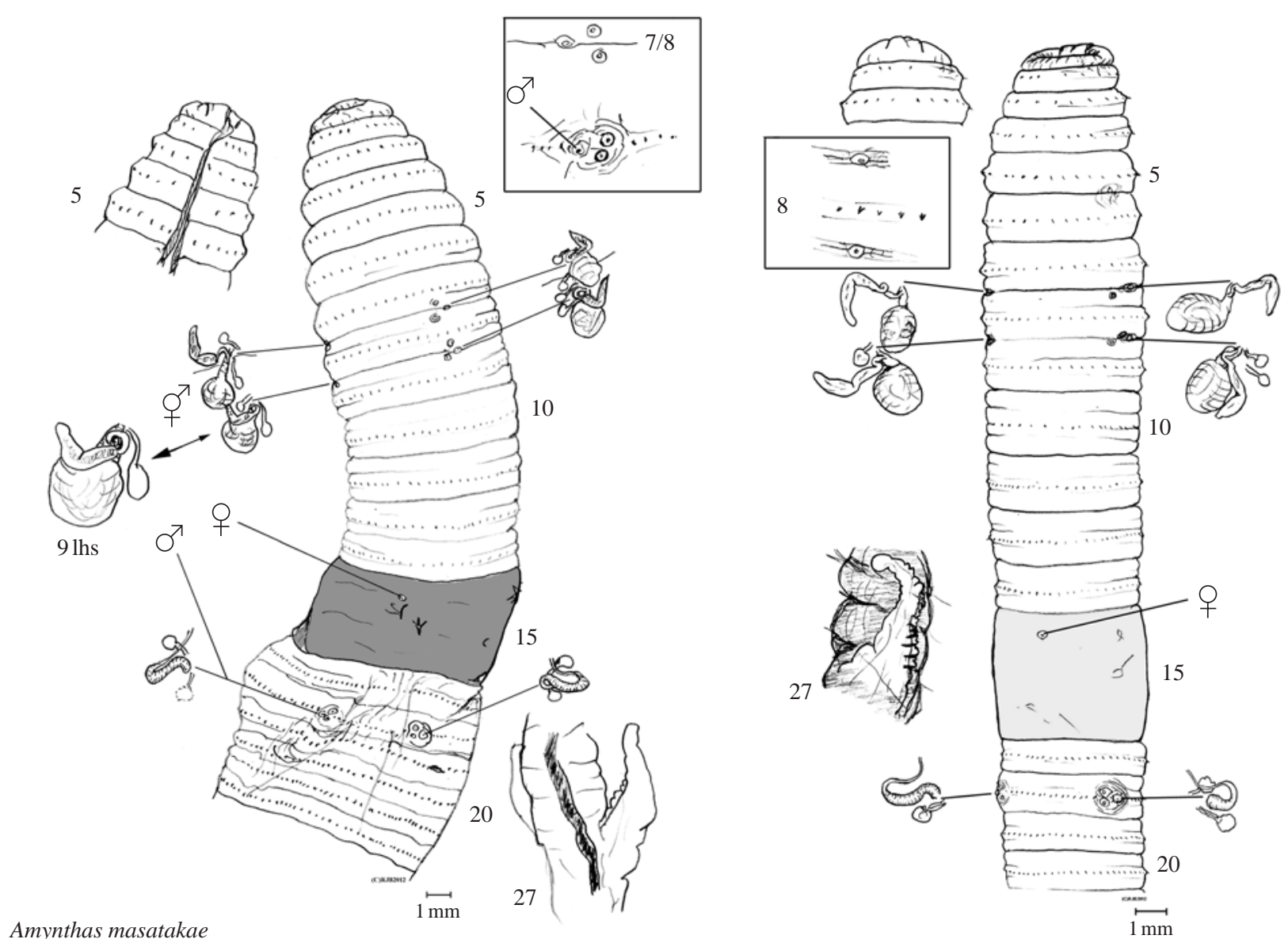

Fig. 1. Amynthas masatakae lectotype (912), dorsal view of prostomium, ventral view of body with spermathecae and prostatic ducts in situ, intestinal caeca and an enlargement of $9 \mathrm{lhs}$ spermatheca from a separate vial [boxed are X2 details of spermathecal pore $7 / 8 \mathrm{lhs}$ and male pore $18 \mathrm{lhs}$ of paralectotype (913)]-lhs; Nogeyama specimen [boxed X2 enlargement of its pores in 7/8/9lhs]-rhs.

Kobayashi). Spermathecal pores lateral in $7 / 8$ and $8 / 9$. Clitellum annular, 14-16. Female pore single on 14. Male pores superficial on 18 with 9-15 setae intervening. Genital markings small papillae, most with glands internally, typically immediately median to spermathecal pores anteriorly and posteriorly, i.e. in some of 7-9 (Kobayashi has them sometimes in successive segment 10); each male pore typically with two genital papillae just median, one presetal and one postsetal on 18 (Kobayashi has some in 19 too). [Note that in the Nogeyama specimen (Fig. 1) some markings lacked internal glands while at least one gland had no noticeable external manifestation, i.e., their pores may be superficial and easily overlooked and not all papillae appear to have glands].

Septa 5/6/7 and 10/11-13/14 thickened; 8/9/10 absent around muscular gizzard. Hearts in 10-13. Spermatheca paired in 8 and 9 each with oval ampulla and elongate or paprika-shaped diverticulum (GM glands often nearby). Testis in sacs in 10 and 11, seminal vesicles paired anteriorly in 11 and 12, pseudovesicles in 13 (what Beddard calls 'egg-sacs' and Ohfuchi an 'ovisac'). Ovaries in 13, ovisacs absent from 14 (pers. obs.). Prostate glands absent with only curved prostatic duct in 18 (or present in some of Kobayashi's specimens), GM glands adjacent. Intestine from $15,1 / 215$, caeca simple with jagged inner edge originating from 26-28 [or simple and without indentations in Kobayashi's (1938: 138) specimens], vascular and lamellar typhlosole starts from around 26-30 (in lectotype and Nogeyama specimen, pers. obs.) with guts mostly containing amorphous soil with some grits (geophagous diet).

Behaviour. Ohfuchi (1938: 62) reported mostly clitellate specimens from organic soil near houses at $12-16 \mathrm{~cm}$ depth in Feb., 1937 that he thought indicative of hibernation.

Distribution and habitat. "Japan" (Beddard); Michaelsen (1903: 97) gave locality as Kamakura [mistakenly quoted by Kobayashi (1938: 139) as "Yokohama"] but this just for its erstwhile junior synonym, $P$. campestris; the report by Ohfuchi (1938) is from Wakayama-ken on the Kii Peninsula in the Kansai region. New material found at Nogeyama in Yokohama, between Tokyo and 


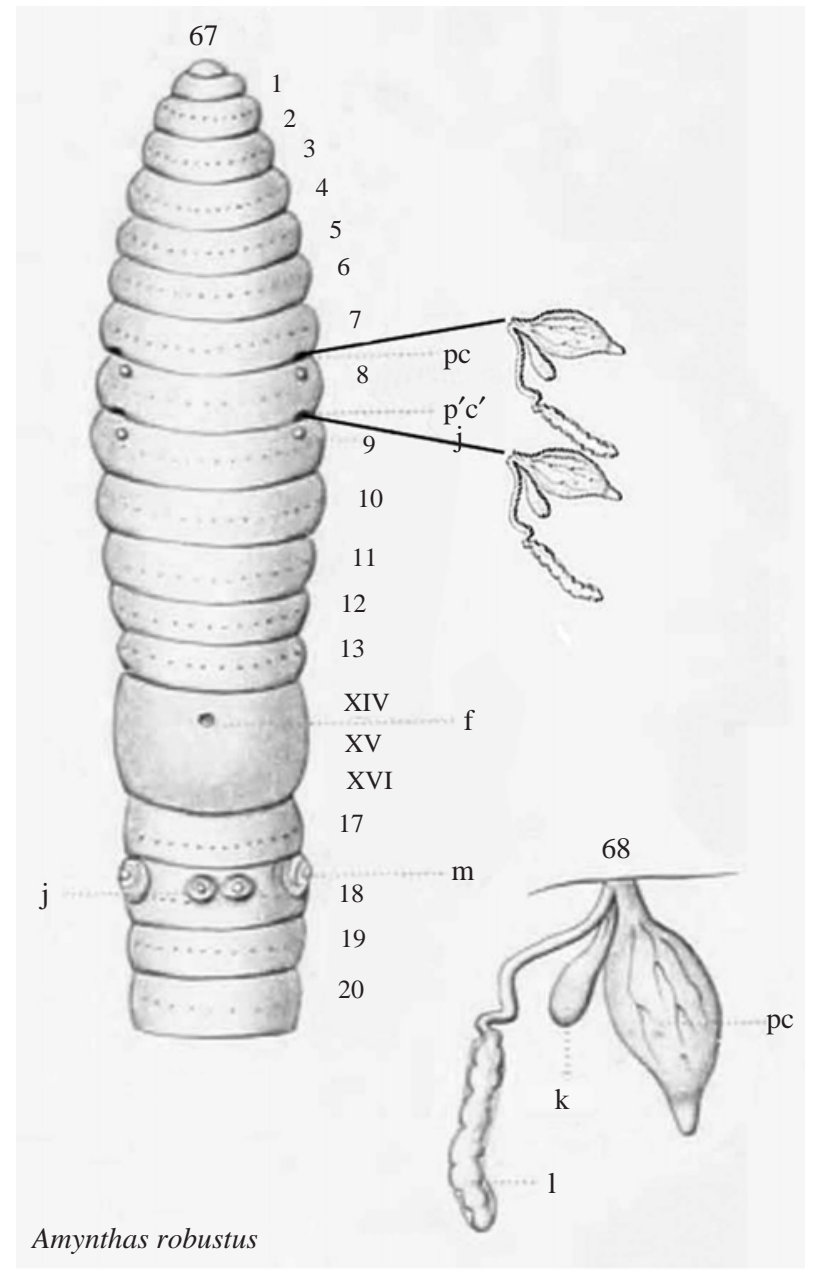

Fig. 2. Amynthas robustus type after original illustrations (Perrier, 1872: figs. 67-68).

Kamakura, suggests an original location. For Korea, Kobayashi $(1937,1938)$ recorded it from Quelpart (=Jeju), several other smaller islands and from the mainland at Mokpo but, in light of current knowledge presented in the current paper, these are possible misidentifications of A. tralfamadore (or M. ryunome?) or some other taxon as noted in Remarks below.

Chuang \& Chen (2002) newly reported A. masatakae as an introduction to northern Taiwan at Mt Dongyan (1000 m elevation on fruit farms) but were mistaken to say this was the first record outside Japan (cf. Kobayashi, 1937, 1938).

A. masatakae is now more restricted in its distribution compared to its treatment whilst in synonymy of $A$. robustus variously by Gates (1939), Ljungström (1971) and successively (cf. attempts to unravel the confusion of $A$. robustus by Blakemore, 2003, 2010b and herein).

Remarks. When we carefully read Gates' (1939: 474) voluminous account of Pheretima robustus we discover that in some cases he only considered citations of some species to be synonyms and, in other cases, the species themselves, these barely differentiated. Thus he claimed the Korean record of "1937. Pheretima masatakae KoBAYASHI, Sci. Rep. Tohoku Univ., ser. 4. vol. 11. p. 337" to be in synonymy and ignored all its other citations above, including the type description! Thus Gates (1939) is assumed by de facto default to have falsely given an impression of synonymy of the name P. masatakae in $A$. robustus. This misinterpretation thereby expanded not only the definition of both combined species, but also their ranges. Being an earlier described species, and possibly having parthenogenetic variability in spermathecae and genital markings as introduced by Gates' bizarre scheme, allowed A. robustus in name to collect several synonyms in subsequent work, e.g. by Ljungström (1971) and Easton (1981), for specimens with two (or fewer?) pairs of spermathecae, ultimately accruing about a dozen synonymic names.

Chuang \& Chen (2002: 75) restored A. masatakae. However, the key character these authors gave for separation of A. masatakae from A. robustus-its lack of prostates-is not necessarily valid: Lack of prostates merely indicates parthenogenetic degradation and it is entirely permissible for sexual forms to occur under this species' name, possibly in manifestations not dissimilar to A. robustus or to any of a dozen other taxa, as (validly or invalidly) included under this name by Gates (1939) and successively (full A. robustus synonymy provided in Blakemore, 2010b).

Meanwhile, Amynthas campestris (Goto \& Hatai, 1898: 67) has prostatic glands, but its synonymy by Beddard (1900) is unacceptable, due not to its glands but rather to the fact that its spermathecal pores are possibly closer together, and, moreover, its GMs certainly differ being post-setal pairs in $7 \& 8$ and 17-19 approximately as wide as the spermathecal pores in 7/8/9. Its true relationship to A. robustus is yet to be determined.

Conversely, Ohfuchi's (1938: 65) suggestion that closely similar A. parvicystis (Goto \& Hatai, 1899: 18) is not a synonym of $A$. masatakae merely because spermathecae in the former were said to be located in $7 \& 8$ while in the latter they are in $8 \& 9$, is perhaps less of a valid reason due to known flaws in his mentor Hatai's work whereby he frequently miscounted segments (e.g. for $A$. carnosus as shown in Blakemore, 2012a). Described with spermathecal pores anteriorly in $7 \& 8$ and with GMs in 6/7/8 (their fig. 8, here Fig. 3), but these are probably vice versa transposition mistakes (i.e., spermathecae in 6/7/8 and markings in $7 \& 8$ ) making it superficially similar to A. tokioensis. Then again, the spermathecal pores may be mistaken (as for their $P$. vesiculata and $P$. carnosa!) and actually occur in $7 / 8 / 9$, in which case this name is possibly a synonym of $A$. masatakae proper. 


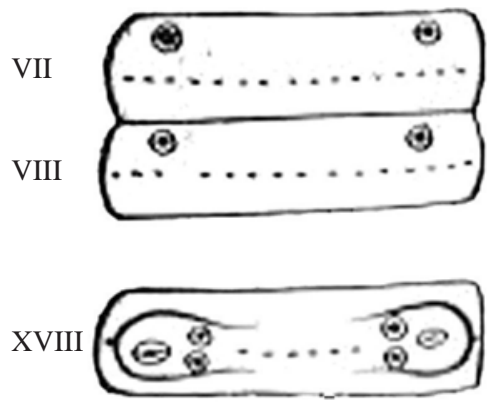

Fig. 8

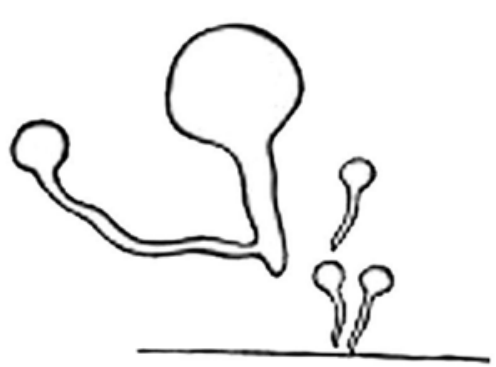

Fig. 8a

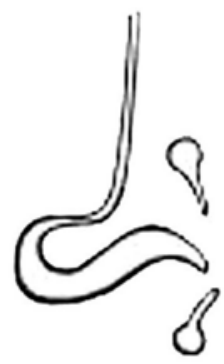

Fig. $8 \mathrm{~b}$
P. parvicystis

Fig. 3. Amynthas parvicystis after original (Goto \& Hatai, 1899: fig. 8)-possibly a composite for different species and with segments $7 \& 8$ miscounted?

In an instance of further confusion, Hatai in Goto \& Hatai (1899) described A. parvicystis with a single pair of caeca having "external margins frizzled" said to be similar to the condition found in Amynthas digitatus (Benham, 1896) and A. bonthainensis (Benham, 1896). Sims \& Easton (1972: 173, fig. 1I) show A. digitatus with multiple (=manicate) intestinal caeca although Hatai may not have known this. Moreover, Goto \& Hatai (1899: 23) failed to include A. parvicystis in their list of species with manicate caeca (although they also miss their own agrestis and mistakenly include divergens in this list), and they had earlier overlooked the caeca of their P. iizukai as well as misdescribing the multiple caeca of their P. megascolidioides. Possibly the caeca were single but incised and if so, plus its spermathecae were really in $8 \& 9$, then it would be similar to specimens reported from Kyushu by Yasuaki Sugi (unpublished http://www.geocities.jp/ homantaro/AmyMeta/AmyMeta1.doc, http://www.geo cities.jp/homantaro/AmyMeta/Robustus.htm, April, 2012) under the name "Amynthas robustus (Perrier, 1872)?" that are, however, now seemingly closer to A. masata$k a e$ as revived herein.

Nothing resembling Goto \& Hatai's A. parvicystis has been reported since its original definition [except for a dubious report by Kobayashi (1941a)] and, although it is probably a poorly-described junior synonym of $A$. masatakae, if its caeca are indeed manicate, most likely it is yet another synonym of $A$. tokioensis [for which Ishizuka's $P h$. verticosa is also a synonym with his figures (Ishizuka, 1999b: 50, figs. 75-83) complying almost exactly with Goto \& Hatai's parvicystis figures]. Perhaps the most sensible policy, for the time being at least, is to treat $A$. parvicystis as a species incertae sedis or dubius.

In the present author's current view, the way that $A$. robustus proper differs from Beddard's A. masatakae, according to Perrier's original description and figures (presented here as Fig. 2) are its genital markings in 8 \& 9 directly below the spermathecal pores plus a pair midventrally and presetally between the male pores. The spermathecal diverticula also appear longer (Fig. 1 vs. Fig. 2). Another differentiating characteristic, as described by Perrier (1872: 116) is "deux coecums lisses" (two smooth caeca) from segment 26 , while the inner edge of the caeca in A. masatakae are indented or serrate. Compare this to Kobayashi's (1938) account where the caeca are without indentations, and to Ohfuchi (1956) who describes serrate caeca plus markings between the male pores, and see A. tralfamadore and M. ryunome herein. Gates (1939: 479) has his "Pheretima robusta" with caecal margins incised but this not based on its types and, as already noted, his work is very confused (he provides no figures), quite unreliable (his errors go unchecked) and highly suspect.

Types of Amynthas robustus will need to be checked for details of genital markings, spermathecae and smoothness of their caeca. Without inspection of these, Gates (1939) then Ljungström (1971) discussed supposedly parthenogenetic forms of Pheretima robusta, and considered (parts?) of both P. aspergillum and P. masatakae to be synonymous. However, types of A. masatakae (Fig. 1) and some specimens (including some of Kobayashi's Korean specimens that seem mostly compliant despite some retaining prostates) from the synonymy presented above, differ from A. robustus in their markings being typically small and paired mesially on inner sides of spermathecal and/or male pores, but typically not midventral on 18.

Kobayashi (1937) described "masatakae" specimens from Korea, some with prostates, that lacked marking between the male pores as in masatakae yet had smooth caeca as in robustus (and ryunome herein); conversely, Ohfuchi (1956: 155, 160) described prostatic "masata$k a e$ " specimens from Okinawa having both mid-ventral markings on 18 as in robustus and serrate caeca as in masatakae. Ohfuchi confounded his descriptions by putting these specimens under two names: "Pheretima masatake" [sic lapsus pro masatakae] and P. lauta Ude, 1905: 405- this latter with synonyms $P$. siemsseni Michaelsen, 
1931: 17 and P. fokiensis Michaelsen, 1931: 19 types of which were inspected by Gates (1939: 420) under the species name Pheretima aspergillum (Perrier, 1872) along with its other erstwhile synonyms $P$. takatorii (Goto \& Hatai, 1898) and $P$. corrugata Chen, 1931: 131. This latter taxon was also allegedly redescribed by Ohfuchi (1956: 162) from Okinawa.

Nevertheless, it seems likely that both Kobayashi (1937; 1938) and Ohfuchi (1956) were describing specimens that would now qualify for neither A. robustus nor A. masatakae, i.e., they possibly represent one or more new and undescribed taxa (cf. Amynthas tralfamadore and Metaphire ryunome herein).

Thus, while appearing intermediate between robustus and masatakae, yet possibly more compliant with the former, these Okinawan and Korean specimens require revaluation with all earlier species' types and also with Taiwanese specimens attributed to either species names of robustus or masatakae, allowing in each case for parthenogenetic degradations (as noted by Blakemore, 2003), i.e., with reduced relevancy of prostates, spermathecae and GMs as key defining characteristics.

Intestinal caecal indentations are perhaps unreliable characters too and may vary interspecifically (as noted by Sims \& Easton, 1972 and Blakemore, 2003). Moreover, Amynthas aspergillum (Perrier, 1872) should, for the time being at least, remain separate retaining its supposed synonyms: Perichaeta takatorii Goto \& Hatai, 1889 and Pheretima paraglandularis Fang, 1929, albeit Chen (1959: fig. 13) shows its intestinal caeca deeply incised whereas Chang et al. (2003: fig. 9) have them smooth.

It is further possible that $A$. robustus proper has nonsuperficial male pores in which case it would qualify for genus Metaphire as for M. ryunome sp. nov. below.

\section{Amynthas micronarius (Goto \& Hatai, 1898) \\ [Figs. 4-6]}

Perichaeta micronaria Goto \& Hatai, 1898: 74, text fig. 1, tab. 1. From Tokyo. Types, none previously known; now Neotype An446 in NSMT Tokyo.

Pheretima micronaria: Michaelsen, 1900: 316 ("perhaps belonging in P. divergens"); Ohfuchi, 1937: 50, text fig. 8, Pl. I, photo. 8; Ohfuchi, 1957: 245 (misspelled "micronalia"); Ishizuka, 2001: 79, fig. 40 (wrong genus, segments miscounted).

Pheretima obtusa Ohfuchi, 1957: 244, fig. 19. From Sonai, Sakishima, Ryukyu. Types?

Amynthas micronarius: Sims \& Easton, 1972: 235; Easton, 1981: 54 (syn. ?shimaensis, ?yamizoyamensis, ?obtusa); Blakemore, 2003: 21 (syn. ?shimaensis, ?yamizoyamensis, ?obtusa; ?tamaensis, hinoharensis, ?hypogaea, ?edoensis); Blakemore \& Ueshima, 2011: 67.

[Pheretima imperfecta Ishizuka, 1999d: 229, figs. 1-7. Syn. nov.? Described as either lacking spermathecae, or having them adiverticulate in $5 / 6$ (one side), or $7 / 8$ (one side); genital markings absent; caeca simple; size range $49-92 \mathrm{~mm}$. The condition in the holotype is not explicitly stated and this name may be a 'grab bag' of degraded morphs that require comparison with $A$. oyuensis (Ohfuchi, 1937)].

Pheretima tamaensis Ishizuka, 1999d: 231, figs. 8-17, tab. 1 (that mistakes the position of each genital marking). [Miscited as "Ishizuka, 2000" in Ishizuka (2001: 69). Poorly described but with spermathecae adiverticulate in 6/7/8; male pores, if present, superficial (at least in type); genital markings absent, or in some of 17/18/19 median to male pore line (when present); prostate glands absent (always?); intestinal caeca simple. Size: $60-90 \mathrm{~mm}]$. From Tokyo region.

[Pheretima stipata Ishizuka, 1999d: 236, figs. 34-40, tab. 3. Syn. nov.? Spermathecal pores 6/7/8/9. GMs in 18 combined with male pores, possibly parthenogenetic artefact, as in its junior synonym $P h$. octo Ishizuka, 2000. From Tokyo].

Pheretima hypogaea Ishizuka, 1999d: 234, figs. 24-33, tab. 2. [Same as micronarius and tamaensis but with three pairs of spermathecae in 6/7/8/9]. From MeijiJingu and Ueno Parks in Tokyo, i.e., the same as typelocality of micronarius.

Pheretima elliptica Ishizuka, 1999d: 237, figs. 41-48, tab. 3. Syn. nov. [Same as micronarius, tamaensis etc. with three pairs of spermathecae in 6/7/8/9 but lacking genital markings (always?)]. From University of Tokyo (near Ueno), i.e. same as type-locality as micronarius.

Pheretima rufidula Ishizuka, 2000a: 15, figs. 8-14, tab. 1. Syn. nov. [Misspelt "P. rufidura" in Ishizuka (2001: 14, 30). GMs absent]. From Takao in Tokyo too.

Pheretima semilunaris Ishizuka, 2000a: 18, figs. 30-36, tab. 1. Syn. nov. [As A. nonsilvestris Blakemore, 2010 but lacking diverticula]. From Tokyo.

[Pheretima subterranea Ishizuka, 2000a: 22, figs. 48-56, table 3. Syn. nov? Also lacking GMs; all diverticula states present in one worm!]. From Tokyo too.

[Pheretima octo Ishizuka, 2000a: 31, figs. 81-89, tab. 1. Syn. nov? Spermathecal pores 5/6/7/8/9. GMs in 17 (18?) combined with male pores, as in senior synonym P. stipata Ishizuka, 1999 that has almost word-for-word justification. From Tokyo].

Pheretima edoensis Ishizuka et al., 2000: 181, figs. 2-8. [Variously miscited and misdated as "Ishizuka, 1999" or "Ishizuka, 2000" in Ishizuka (2001: 11, 54, 76, 101) for a figured specimen that, although misplaced in a section of species having four pairs of spermathecae, has only three pairs in 6/7/8/9, yet its GMs appear to comply with those of A. micronarius, etc.]. From Imperial Palace, Tokyo, i.e., same type-locality as micronarius.

Pheretima hinoharensis Ishizuka, 2000b: 187, figs. 35- 

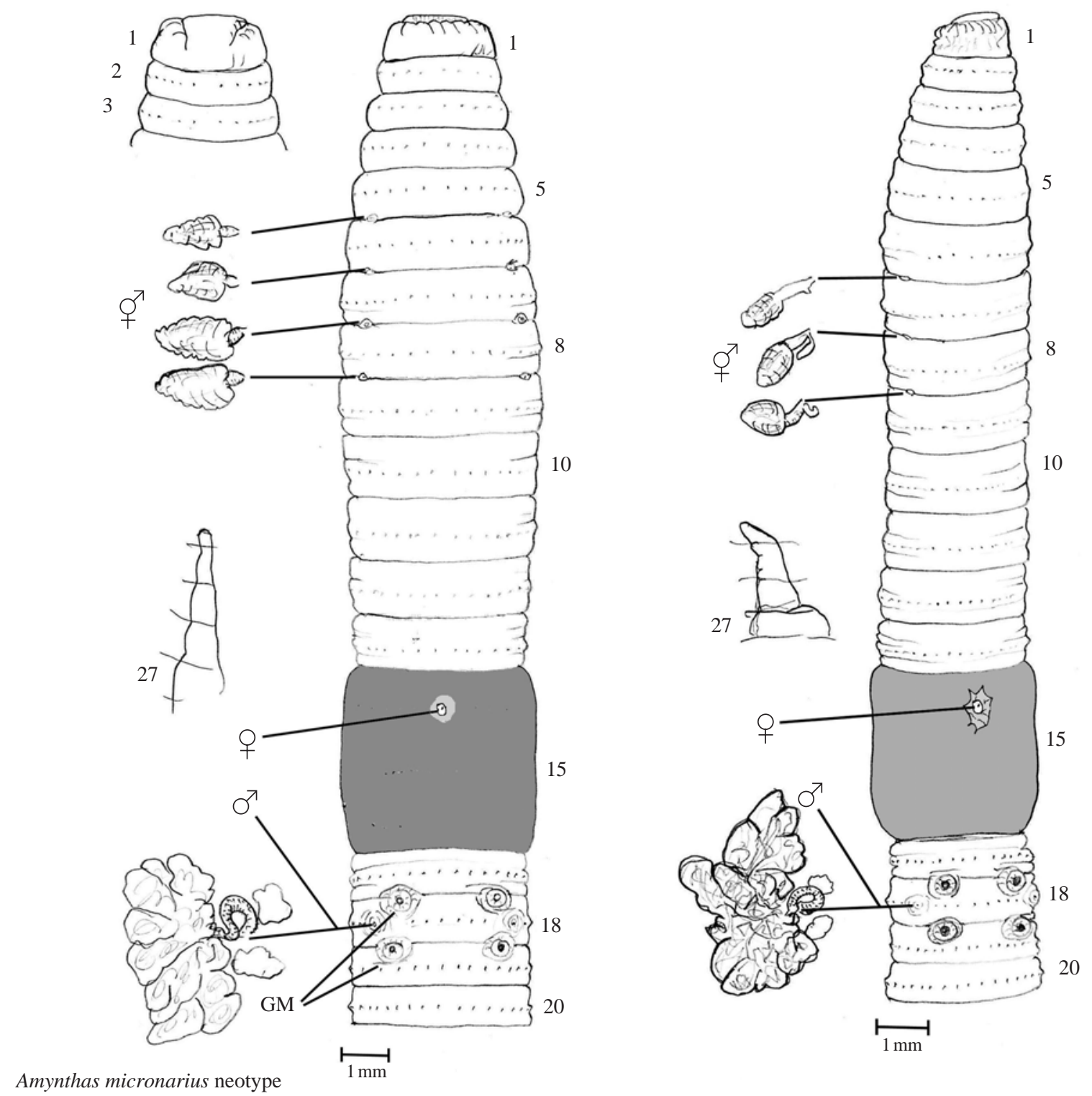

Fig. 4. Amynthas micronarius neotype NMST An446-lhs; specimen NMST An445 - rhs.

42, tab. 1. [Misspelt "hinoharaensis" in Ishizuka (2001: $11,18,78,101)$. Spermathecal pores in 5/6/7/8/9, often proceeded by a small glandular pore, and with markings in $17 / 18 \& 18 / 19$ as in A. micronarius. Possibly an amphimixic morph. The garbled Remarks justifying this species make little sense]. From Itsukaichi (not Hinohara?) on outskirts of Tokyo.

['Pheretima' palarva Blakemore, 2003 (nom. nov. pro Pheretima parvula Ishizuka et al., 2000a: 186, figs. 17-24 [non Perichata parvula Goto \& Hatai, 1898 (?=Amynthas gracilis); nec Pheretima parvula Ohfuchi, 1956 (=Metaphire parvula). Name mis-cited and misspelt as 'Pheretima parvola Ishizuka, 2000' by Ishizuka $(2001: 12,69,102)$ and "P. parvora" by Ishizuka
(2001: 46)]. Syn. nov.? Has "Two pairs of spermathecal pores situated in furrows $6 / 7 / 8$ in ventro-lateral sides, and occasionally absent, variable in number, separated by a distance of ca. 1/3 body circumference." It lacks GMs and often one or both male pores, thus it could actually be any of a number of prior species but may well comply within a broad diagnosis of $A$. $m i$ cronarius. From (Imperial Palace) Tokyo, i.e. same locality as edoensis synonym of micronarius. Recombined as "Amynthas palarvus" in Blakemore (2010a: 193), as a 'nonsense' name, it should actually be maintained as A. palarva].

[Amynthas nonsilvestris Blakemore, 2010a: 193 (nom. nov. pro Pheretima silvestris Ishizuka, 2000a: 18, figs. 


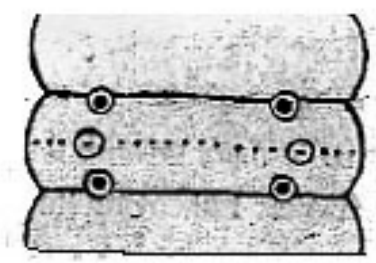

P. micronaria, n. sp.

S. GOTO AND S. HATAT.

35

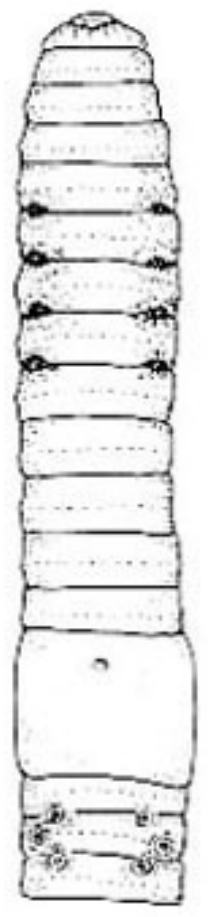

Pheretima hinoharensis
2

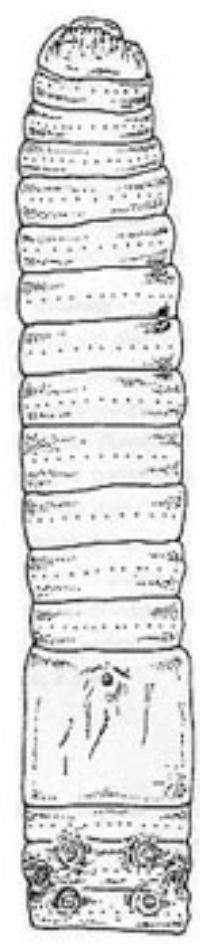

Pheretima edoensis
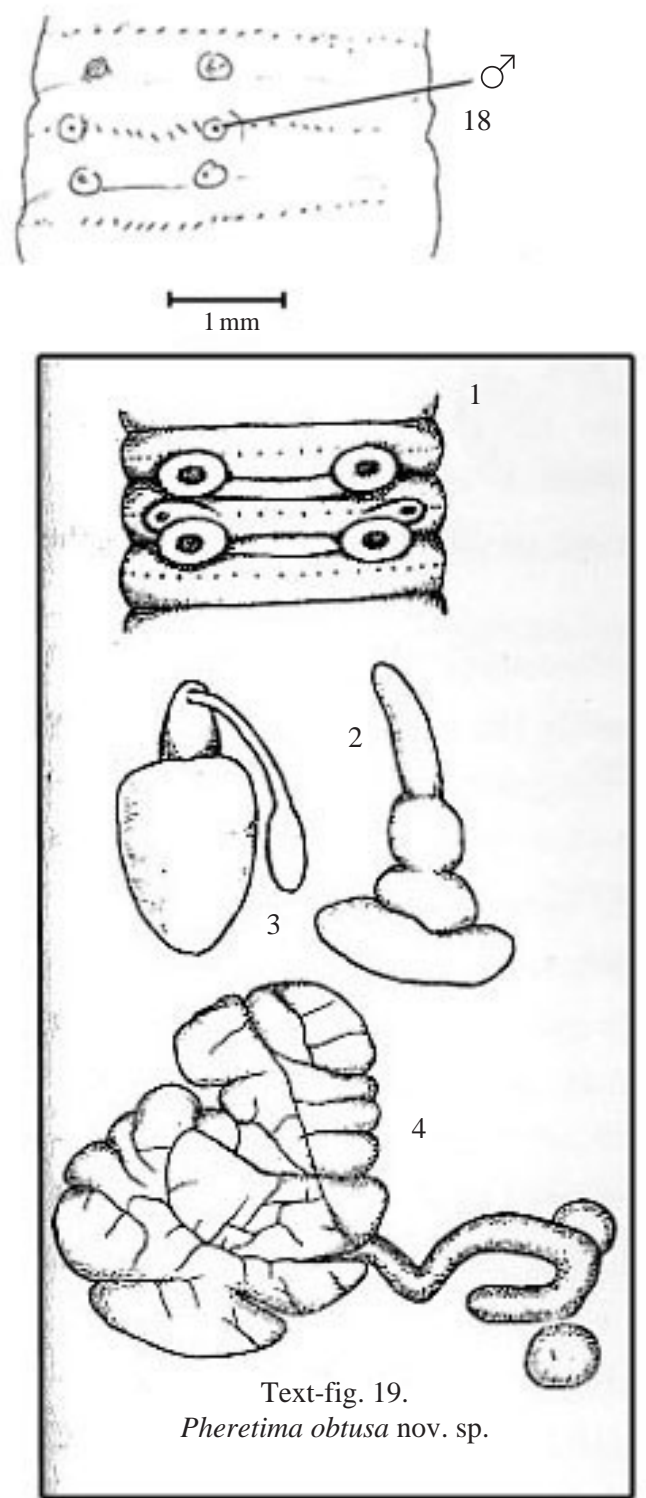

Fig. 5. A. micronarius synonyms with Goto \& Hatai's (1898: fig.1) original-top lhs; male field of specimen UMUTZ-Ann-OG-35 topotype (unproven syntype?)-top rhs; Pheretima obtusa from Ohfuchi's, 1937 text fig. 19-bottom rhs; and Ishizuka's P. hinoharaensis (fig. 35) and $P$. edoensis (fig. 2) synonyms-bottom middle and lhs.

23-29, tab. 1, non Pheretima silvestris Michaesen, 1923). Spermathecal pores 5/6/7/8/9. GMs absent. From Tokyo].

Material examined. Neotype NMST An446 from Saito Ho-on Kai collection: (sample tube \#19) labeled " $\mathrm{Ph} \mathrm{mi-}$ cronaria Goto \& Hatai" with location and collector not noted; one of two previously undissected matures here dissected and sketched $(90 \mathrm{~mm}$ long with markings in 17/18 \& 18/19); the other, specimen NMST An447 (100 $\mathrm{mm}$ long with markings in 17/18 only). Specimen (90 mm long) NMST An445 (tube \#18), a previously undissected mature specimen, here dissected and sketched, label- ed "Ph sp Sendai, Naga-machi, Kamohara's home (in kanji) 16/VI/1931" collector not noted. UMUTZ-AnnOG-35 remnant labels written by Professor S. Goto or Dr S. Hatai had: "Perichaeta micronaria Tokyo" +"No. 4" + "6/91" [June 1891?]; two damaged specimens, seemingly mature, that whilst on loan had been allowed to dry out and are now in poor condition, i.e., contemporaneous topotypes but since neither was dissected they were probable, but not proven, actual syntypes. Also UMUTZAnn-OG-36 labeled "Perichaeta micronaria" with kanji for Meiji 29 and $8^{\text {th }}$ month [=August 1896] from "Tozaki, Kikkuchi, Kumamoto-ken collected by Mr Takiyama"-a batch containing many life stages of Amynthas 

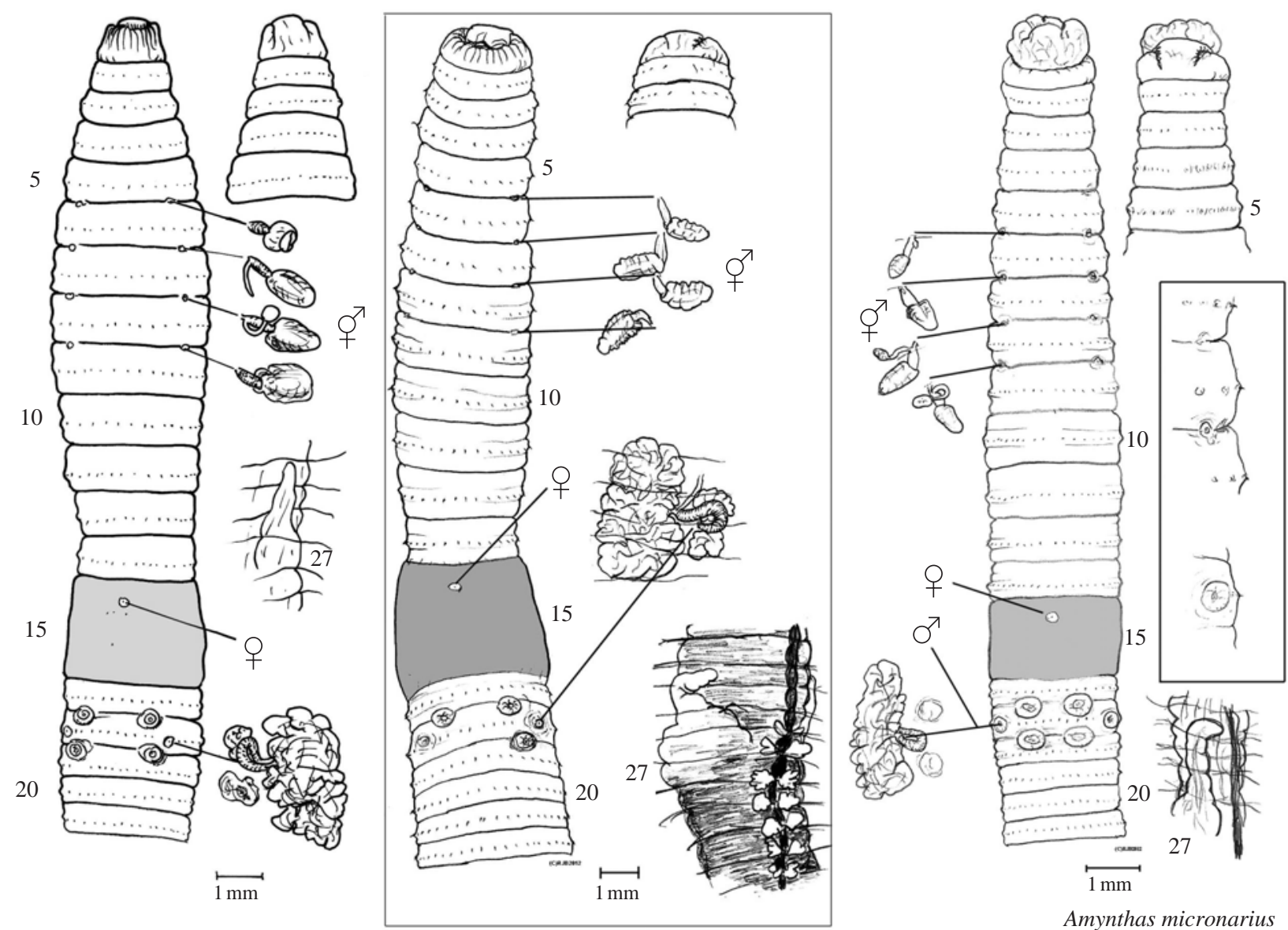

Fig. 6. A. micronarius Japanese Watarase specimen-lhs; Nogeyama specimen-middle; Incheon's NIBR (INV0000246442) Jeju-conservatory specimen [boxed X2 enlargement of spermathecal and male pores in 5/6 rhs \& $18 \mathrm{rhs}$ ]-rhs.

corticis species-complex and possibly A. micronarius with at least one dissected $(110 \mathrm{~mm}$ long and with GMs in $17 / 18$ only) but, as noted by Blakemore \& Ueshima (2011), not syntypes because this was not the stated "Tokyo" type-locality. Note: Both the Tokyo Museum and Tokyo University lots of these historical specimens had been loaned out by Mr Ishizuka since 1981-more than thirty years previously-but their significance was seemingly unrealized and this crucial material was ignored and unpublished without distracting from numerous "new" species, many of which were homonyms and most of which were synonyms as noted above and by Blakemore (2003; 2008; 2012a; 2012b) and by Blakemore \& Ueshima (2011).

A Watarase, Tochigi-ken specimen unregistered in Yokohama National University (YNU), collected by Dr T. Kamitani April, 2003 from his Control site R (dissected and sketched by RJB). Kamakura specimens collected by RJB, Yuko Hiramoto \& Amanda Reed, $12^{\text {th }}$ April 2004 from Kuzuharagaoka Shrine along with seven other species; plus other specimens collected by RJB from bamboo groves and organic farms at Ami, Ibaragi-ken $27^{\text {th }}$ July 2006 (all in YNU collection).

Japanese specimen (NIBR IV0000249941) posterior amputee, mature, collected by RJB and T.J. Tansy $23^{\text {rd }}$ May 2012 from Nogeyama, Sakuragi-cho, Yokohama, Japan.

Korean specimen (NIBR IV0000246442) collected by RJB $19^{\text {th }}$ March 2012 from NIBR Incheon's Jeju Island Biosphere display along with A. tralfamadore Blakemore, 2012 and an immature lumbricid (IV0000246443)this paper's subjects.

Jeju-do Island specimens (NIBR IV0000250396-7) 8 mature specimens, collected by RJB, TaeSeo Park \& Insul, $21^{\text {st }}$ June, 2012 from Hyonyungsa Temple, Mt Halla, Jeju-do (thus newly confirming its presence on the mountain).

Description. Colourless (partly transparent) or pale pinkish grey in life, a light buff or grey in alcohol with clitellum either darker or lighter (some specimens darker). Length ca. $49-120 \mathrm{~mm}$ by $2.5-4.5 \mathrm{~mm}$ with $61-110 \mathrm{seg}$ ments [neotype $90 \mathrm{~mm}$ long with 80 segments; stated as 
either 66 or $55 \mathrm{~mm}$ with either 106 or 102 segments by Goto \& Hatai (1898: 74 vs. tab. 1); Ohfuchi's specimens and Ishizuka's synonyms range 66-119 mm and 90-120 $\mathrm{mm}$, respectively; Ohfuchi's obtusa body lengths vary 49-54 mm]. First dorsal pore (often minute) in 11/12. Setae 25-51 [Goto \& Hatai have 28-32 in spermathecal segments and 35+ more posteriorly; Ohfuchi (1937: 52) details 25-51 in forty-six specimens; Korean specimens have $\sim 40$ on segment 12 and $48+$ further back]. Spermathecal pores four pairs in 5/6/7/8/9 (e.g. neotype) or three pairs in 6/7/8/9 if anterior pair absent (e.g. An445, some Ibaragi specimens and synonyms) or, possibly, fewer spermathecae (synonyms), ca. 0.3 C apart. [Note: Spermathecal circumferencal ratios may be calculated in various ways as from the camera lucida figures but mean little in soft-bodied worms having different preservation techniques]. Male pores superficial on segment 18 with 7-12 setae intervening (Goto \& Hatai say " 8 " but show 10) or absent in some morphs. Genital markings paired anteriorly in 18 and 19 but mostly appearing intersegmental in 17/18 (e.g. specimen An447) or 17/18 \& 18/ 19 (neotype and An445) just median to the lines of the male pores, some morphs lack one or more GMs, but when present glands correspond internally. Prostates as figured (sometimes aborted). Septa 8/9 and 9/10 aborted (sometimes partially). Spermathecal diverticula clavate or variously degraded and/or deleted: often adiverticulate or partially stalked, or small terminal diverticular bulbs may be present (sometimes filled with coagulum but not necessarily iridescent). Hearts in 10-13. Holandric with testis in sacs in 10 and 11 (not always iridescent), seminal vesicles in $11 \& 12$. Intestine from 15 or 16 ; intestinal caeca from 26 or 27 simple with smooth margins; intestinal typhlosole vacularized and lamellar from ca. 26. Gut contains soil with few grits and often charcoal grains, i.e. geophagous.

Behaviour. "The motion of this worm is very active and swift, and when dug from the ground, they wriggle and bounce about very quickly" (Ohfuchi, 1937: 50).

Distribution and habitats. Type-locality in Tokyo. Regarding the neotype, it is unknown but localities of other specimens in the collection included Komaba, Tokyo according to Ohfuchi (1937: 113). A species obviously subject to transportation that masks its origin; in Japan it occurs from Hokkaido to Ryukus (Easton, 1981). Newly recorded from Korea, the NIBR specimen's probable provenance from Jeju, subsequently supported on material recovered at Mt Halla (RJB pers. obs.).

Japanese material from around shrine gardens, farms and other disturbed sites, or "generally found near houses" (Ohfuchi, 1937). Under moss at NIBR Jeju facility. Under rocks at Nogeyama park. In soil near graveyards at $\mathrm{Mt}$ Halla Temple, Jeju.

mt DNA COI data for Amynthas micronarius samples:
Tokyo neotype NMST An446-nil result. Specimens, NMST An445 and An447-nil results.

$>$ WO1 Korean A. micronarius specimen IV0000246442 from NIBR's Jeju biosphere:

TTTATACTTCATCTTAGGGATCTGAGCCGGAAT AATTGGTGCCGGAATAAGATTACTCATTCGAGT CGAATTAAGACAACCCGGACCATTTCTAGGTAG GGATCAACTATACAATACAATTGTAACCGCACA CGCATTCTTAATAATCTTCTTTCTAGTAATGCCA GTATTTATTGGAGGATTTGGAAATTGATTACTA CCTCTAATGTTGGGAACACCAGATATAGCATTC CCACGTCTAAATAACATGAGATTTTGATTATTA CCTCCGTCACTTATTTTACTCGTTTCATCTGCAG CCGTAGAAAAAGGAGCGGGAACAGGGTGAACA GTATACCCCCCGCTAGCAAGAAACATTGCCCAT GCCGGGCCATCAGTAGACCTTGCAATTTTCTCA CTACACTTAGCAGGAGCCTCCTCAATTTTAGGG GCAATTAACTTTATTACTACAGTAATTAACATG CGATGATCGGGACTACGCTTAGAACGAATTCCC CTATTCGTATGGGCAGTCGTAATCACCGTAGTA TTACTTCTTCTATCACTACCAGTATTAGCGGGA GCCATTACAATACTTCTTACAGACCGAAACCTT AACACATCGTTCTTTGATCCAGCAGGTGGGGGG GACCCTATTCTATACCAGCACCTGTTTTG

BLASTn ver. 2.2.26+ (http://www. http://blast.ncbi.nlm. nih.gov/June, 2012):

Identities $=634 / 634(100 \%)$, Gaps $=0 / 634(0 \%)$ for GenBank AB542498-AB542501 "Amynthas micronarius" vouchers from Miyagi, Niigata, Hyogo and Kagawa-ken, Japan (http://www.ncbi.nlm.nih.gov/genbank/June, 2012). Thus identity is supported.

Remarks. Ishizuka's Pheretima hinoharensis is likely synonymous (previously in Amynthas corticis speciescomplex), the glands near the spermathecal pores rather irrelevant in parthenogenetic polymorphs, or possibly underdeveloped or overlooked in other specimens. Moreover, Ishizuka's Pheretima hypogaea and P. edoensis with three pairs of spermathecae are exactly similar, and so too is his P. tamaensis with two (adiverticulate) pairs. All three are mere morphal variations belonging to Goto \& Hatai's prior taxon. Anterior spermathecae in 'typical' specimens of $A$. micronarius are often atrophied as if in the process of disappearing as indeed often occurs, indicative of involvement in a polymorphic complex. Thus two other NSMT specimens are mostly identical to the neotype (An446), apart from one (An445) lacking the anterior pair of spermathecae and one (An447) having markings in $17 / 18$ only.

The new Korean and Japanese specimens comply with the species diagnosis, including figured specimens from Watarase and NIBR (as also in the $P$. subterranea synonym), where one worm has all three spermathecal diverticula states: from diverticulate or stalked only to adiverticulate, demonstrating the inconsequence of this character. 
The current synonymy above now requires comparisons with Korean Amynthas bamsagolensis Hong \& James, 2001 that, following Blakemore (2012a), is held under $A$. carnosus (Goto \& Hatai, 1899), and with A. sangumburi Hong \& Kim, 2002: 198 also from Jeju Island that appears an indistinguishable syn. nov. of Amynthas subrotunda (Ishizuka, 2000) comb. nov. itself provisionally held in an Amynthas corticis species-complex in a review by Blakemore (2003) 10 years earlier.

Amynthas shimaensis and A. yamizoyamensis are retained as described below.

\section{Amynthas tralfamadore sp. nov.}

[Fig. 7]

Diagnosis. Amynthas with spermathecal pores lateral in 7/8/9. Genital markings near spermathecal and male pores. Intestinal caeca simple with rugose inner face from 27. Spermathecal diverticula rounded rather than elongate and dorsal pores from 9/10.

Material inspected. Holotype (H), NIBR IV0000246 441 , mature specimen fixed and stored in $80 \%$ ethanol (EtOH), here dissected and figured (Fig. 7), collected 19.III.2012 by RJB \& JooLae Cho of NIBR.

Etymology. After writer Kurt Vonnegut's fictional biosphere reserve and exhibition.

Description. Length $125 \mathrm{~mm}$, segments 125 . A dark chocolate brown anterior dorsum with faint mid-dorsal line, clitellum darker and ventrum pale. Dorsal pores minute in 9/10 open from 10/11. Setae 46-50 per segment around segment 12, up to ca. 70 after clitellum. Spermathecal pores ca. 0.4 circumference apart in 7/8/9. Genital markings as small opposed discs just median to spermathecal pores paired either side in $7 / 8$ (only one unilateral after $7 / 8 \mathrm{rhs}$ ) and in 8/9 (plus one 'rogue' unilateral after 9/ 10lhs); similarly on either side of 18 just ventral to flat male pores.

Internally, small stalked glands correspond to the external genital markings. Peptonephridia fill 5 and 6, septa to $7 / 8$ are thin and absent in $8 / 9 / 10$ where muscular gizzard occurs, and after this they are also thin. Nephridia meroic. Spermathecae in 8 and 9 each having round ampulla on short duct with rounded clavate diverticulum. Dorsal vessel single; hearts in 10-13. Metandric, testis possibly reduced in 10 but only found in 11 and there not iridescent; seminal vesicles larger posteriorly in 11 and smaller anteriorly in 12. Ovaries and funnels in 13. Prostate glands aborted and only short muscular ducts remain. Oesophagus only slightly dilated in $14-1 / 215$; intestine origin in 16 with simple caeca from 27 that are unusual in having a paler rugose and capillaried interior face extending forward to ca. 24. Thin lamellar typhlosole commences around 27. Gut contains organic soil and larger grits.

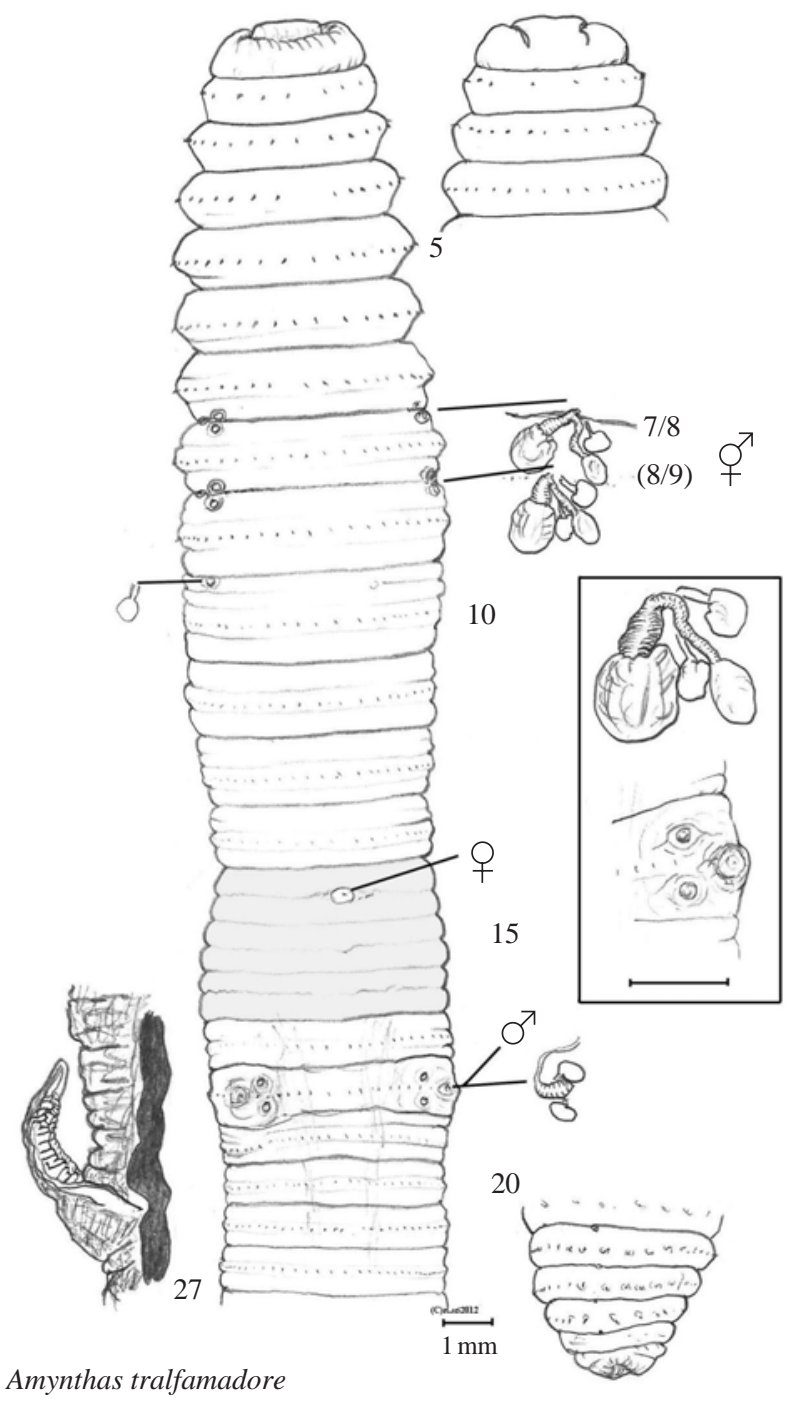

Fig. 7. Amynthas tralfamadore sp. nov. holotype from NIBR Korea; [boxed is a X2 enlargement of 9 lhs spermatheca and $18 \mathrm{rhs}$ male pore].

Distribution. Korea, Incheon NIBR facility, possibly introduced from Jeju Island.

mtDNA COI Barcode result:

$>$ WO2 A. tralfamadore Holotype IV0000246441 from NIBR's Jeju biosphere:

GTGTTGGTATAGGATTGGATCTCCCCCTCCTGC TGGATCAAAGAATGATGTATTGAGGTTTCGATC TGTTAGTAATATGGTAATTGCCCCTGCCAGTAC AGGTAGGGACAATAGTAATAGTACTACAGTGA TTACTACTGCTCACACAAATAGTGGGATTCGTT CTAGACGTAACCCAGATCATCGTATGTTAATTA CTGTTGTGATAAAGTTAATAGCTCCAAGAATTG ACGAGGCACCTGCAAGATGAAGTGAGAAAATT GCAAGGTCTACTGAAGGACCGGCATGTGCTATA TTTCTTGCTAAGGGTGGGTAAACTGTTCAACCT GTGCCAGCCCCCTTTTCTACCGCGGCAGATCTT 
ACCAATAAAATTAATGATGGCGGGAGTAGTCA AAATCTTATGTTATTTAATCGAGGGAACGCCAT ATCTGGGGTTCCAAGTATTAGGGGTAGTAACCA GTTTCCGAATCCACCAATAAATACTGGCATTAC TAGAAAGAAGATTATTAAAAATGCATGTGCTGT TACAATTGTATTATATAGCTGGTCCCTACCAAG GAAGGATCCAGGTTGTCTTAACTCAATACGAAT AAGTAGTCTTATTCCTGCACCAATTATTCCTGCT CAAATTCCTAGAATAAAGTATAGGG

megaBLAST showed no match better than $94 \%$ for voucher specimens, neither based on types, of AB542 533 "Amynthas robustus" from Japan or EF077538 "A. triastriatus" from China (an erstwhile synonym of $M$. masatakae), or only $85 \%$ of max identity for DQ224191 "A. robustus" from Taiwan (cf. M. ryunome sp. nov.).

Remarks. A parthenogenetically degraded species, lacking prostate glands as with A. masatakae, nevertheless, in the key of Sims \& Easton (1972) its incipient metandry corresponds to an A. martiorum-group. If holandric it would approach the large A. aeruginosus-group that contains both $A$. robustus and A. masatakae.

Distinctive characteristics of A. tralfamadore are the shape of spermathecae with the diverticula bulb spherical rather than elongate as in A. robustus or "paprikashaped" in A. masatakae-although the importance of this in parthenogenetic morphs is perhaps debatable-and its inner face of intestinal caeca perhaps more rugose than in A. masatakae types. Moreover, its paired sets of markings in 18 are slightly wider apart on each side compared to those in the A. masatakae types (Fig. 1). Its mtDNA COI barcode data serves to definitively characterize this species.

Although type-locality is the NIBR facility, its origin has yet to be clearly determined. The Jeju-do display uses bagged potting soil for bulking, but worms may have been accidentally introduced around roots of trees and shrubs and flowers directly imported from the Island or indirectly via plant nurseries.

This survey only took about 10 minutes and probably other species of earthworms are yet living in the facility, despite periodic replacement of the soil (pers. obs.), but a more extensive search was curtailed in order to protect the public display.

\section{Amynthas shimaensis (Goto \& Hatai, 1899) comb. nov.} [Fig. 8].

Perichaeta shimaënsis Goto \& Hatai, 1899: 15, fig. 3, tab. 1. Shima, Kai Peninsula. Type(s) unknown.

Pheretima shimaensis: Michaelsen, 1900: 303.

Material examined. Single mature specimen unregistered in Yokohama National University (YNU) SERG earthworm collection, from high mountain plains, Mt Fuji, Shizuoka-ken, Japan collected $8^{\text {th }}$ November, 1998 by To-

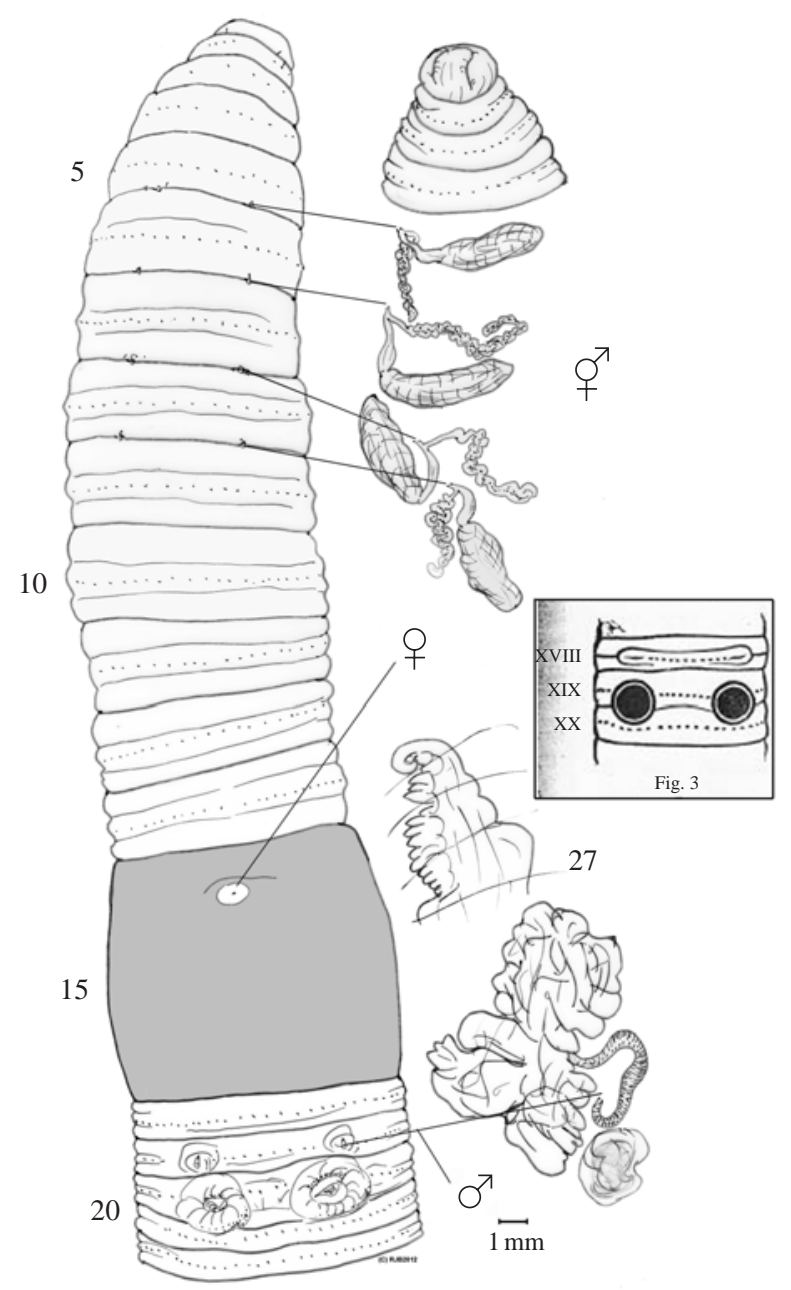

Amynthas shimaensis

Fig. 8. A. shimaensis Mt. Fuji specimen (YNU) [boxed Goto \& Hatai's (1899: fig. 3)].

moko Uchida.

Description. Dark grey dorsum with intersegments not noticeably darker nor paler, clitellum puce in Fuji specimen versus dark flesh colour with darker intersegments in Goto \& Hatai's specimen. Length $150 \mathrm{~mm}$ with 132 segments (205 and 163 segments in Goto \& Hatai). First dorsal pore in 12/13 (Fuji specimen and Goto \& Hatai's account). Setae ca. 50 before clitellum and ca. 60 after in Fuji specimen (Goto \& Hatai have about 85 in the genital segments). Spermathecal pores four pairs in 5/6/7/8/9 about 0.25 of circumference apart. Male pores superficial on segment 18 with about 10-13 setae intervening (Goto $\&$ Hatai have them separated by 13 setae but only show 11 in their fig. 3). Genital markings paired posteriorly in 19 encroaching in 19/20 with solid gland corresponding internally. Septa 8/9 and 9/10 aborted. Spermathecal diverticula clavate and convoluted (or "winding" in Goto $\&$ Hatai). Last hearts in 13. Holandric with seminal vesi- 
cles in $11 \& 12$. Intestine from 15 ; intestinal caeca from 26 or 27 simple with incised ventral margins (in Fuji specimens at least). Lamellar typhlosole from ca. 27 (pers. obs.).

Distribution. Japan, Mie-ken, Kansai [that Easton (1981: 55) mistakes as "GUMMA" (=Gunma-ken) in Kanto], and now possibly Mt Fuji in Shizuoka-ken.

Remarks. Amynthas shimaensis (Goto \& Hatai, 1899) is restored from synonymy in A. micronarius (Goto \& Hatai, 1898). However, the major problem now is that the only difference between A. shimaensis and the prior Amynthas grossus (Goto \& Hatai, 1898: 75) - provisionally in synonymy of A. fuscatus (Goto \& Hatai, 1898: 66) after Easton (1981: 57) along with ten other synonyms from Blakemore (2003: 19) - is posterior markings additional to those in 19 (or absent). Both taxa typically have winding spermathecal diverticula. Although not mentioned by Goto \& Hatai, all these species appear to share incised intestinal caeca, at least in mature worms and, accepting this, the current specimen agrees tolerably with their description of A. shimaensis. Proper resolution requires new material from its Shima, Mie-ken type-locality.

Alternatively, this Fuji specimen may actually correspond to Amynthas grossus once it is separated and removed from A. fuscatus, but such acts are deferred pending further studies from Japan.

Korean Amynthas murayamai (Kobayashi, 1938: 164) is distinguished from $A$. shimaensis redescribed here, in its GMs anteriorly on 19 with no setae intervening, amongst other differences; also its intestinal caeca are smooth edged. Thus it is maintained on the Korean biodiversity list.

\section{Amynthas yamizoyamensis (Ohfuchi, 1935)}

[Fig. 9].

Pheretima yamizoyamensis Ohfuchi, 1935: 413, figs. 610. Mt. Yamizo, Japan. Types?

Amynthas yamizoyamensis: Blakemore, 2010a: 193 (syn. ?conformis).

Note. Name sometimes misspelt "yamijoyamensis" or "yamizoyamaensis".

Material examined. None-fate and location of the original four syntypes unknown.

Description. Pinkish grey colour. Length, 136-177 mm, segments 117-136. Setae 25-48. Spermathecae in 5/6/7/ $8 / 9$. GMs large paired in $17 / 18$. Male pores, superficial but "elevated" and separated by 7-10 setae. Presence of septa 8/9/10 unrecorded. Spermathecal diverticula variable as short stalks to long coiled ducts. Seminal vesicles in 11 and 12. Intestine from 15, caeca simple from 28.

Distribution. Mt Yamizo (1022 m) lies in three prefectures: Fukushima, Ibaragi and Tochigi. A similar if not conspecific Yamanashi-ken specimen (14/2/2003) is

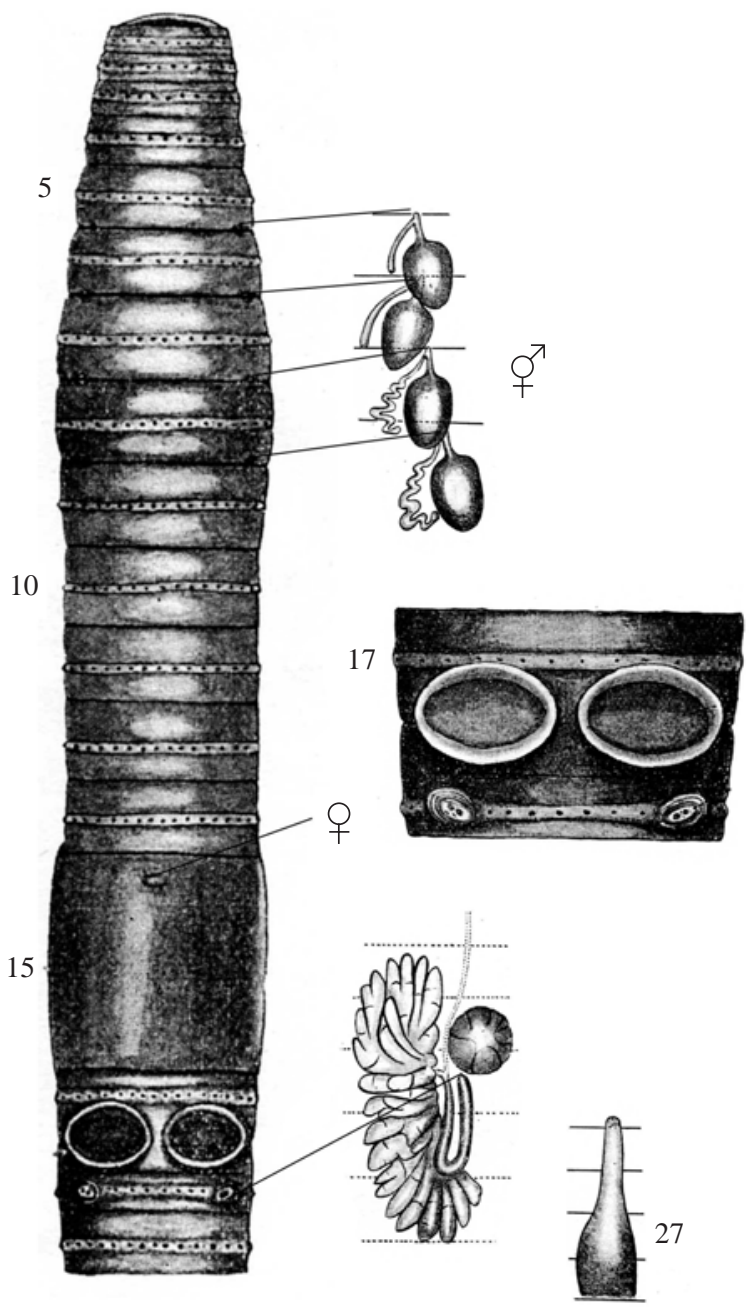

Fig. 9. Amynthas yamizoyamensis after Ohfuchi's (1935: figs. 610) originals.

also in YNU collection although its caeca are slightly incised ventrally.

Remarks. The question of restoration from Easton's (1981: 55) synonymy in A. micronarius mooted by Blakemore (2010a: 193) is here supported.

Genus Metaphire Sims \& Easton, 1972

\section{Metaphire ryunome sp. nov.}

[Fig. 10.]

Material inspected. Holotype (H), NMST An457, mature posterior amputee specimen fixed and stored in $80 \%$ ethanol(EtOH), here dissected and figured (Fig. 10), from Hikone collected 2.II.2011 by RJB and Shiga Uni. students. Paratype (P) NMST An458, mature complete specimen with same collection details, in $80 \% \mathrm{EtOH}$.

Etymology. Japanese "dragon eyes", for the appearance of the male pores. 


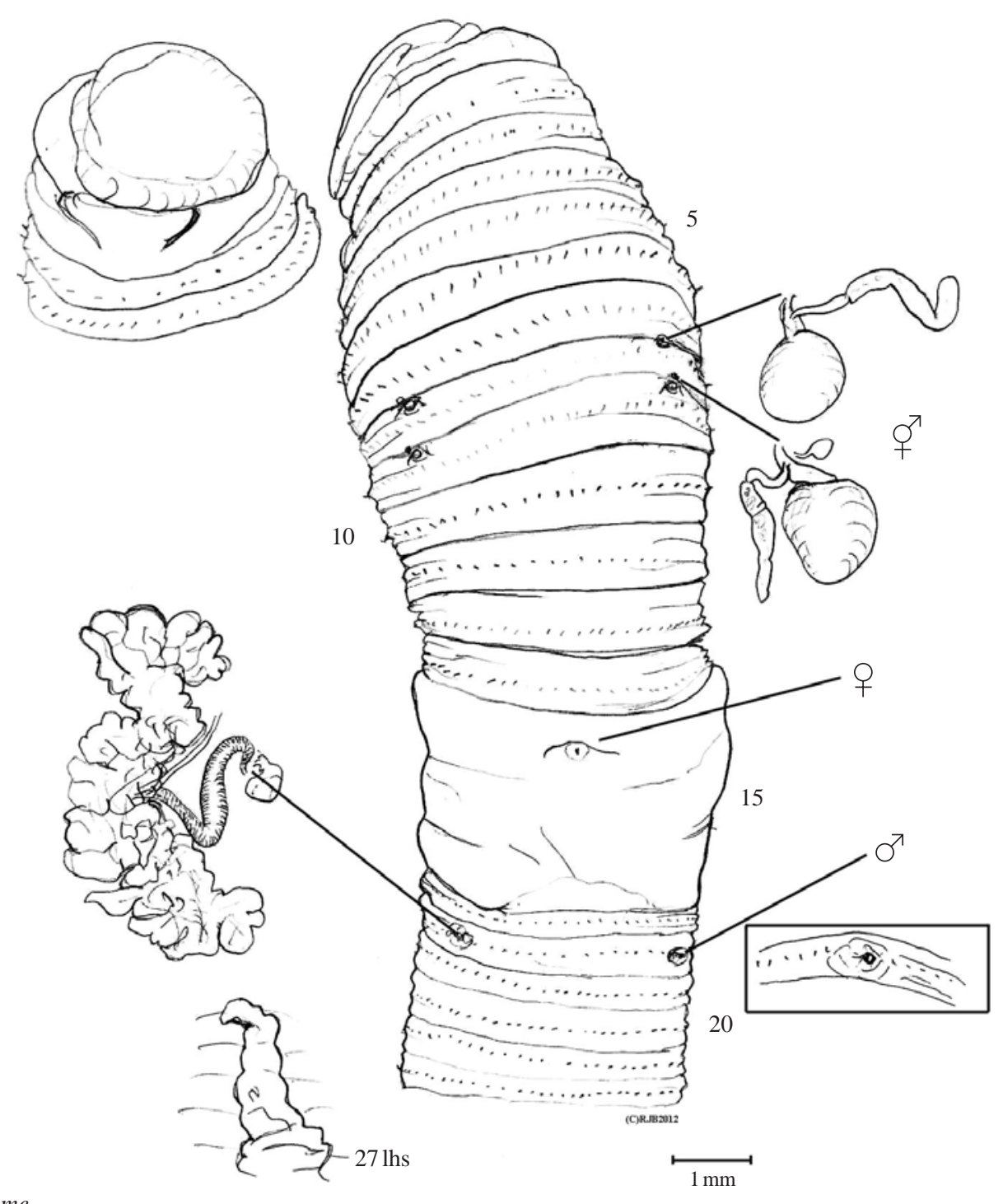

Metaphire ryunome

Fig. 10. Metaphire ryunome sp. nov. from Japan, holotype (its pharynx everted during anaesthesia); [boxed (same scale) is the $18 \mathrm{lhs}$ male pore of the paratype].

Diagnosis. Marginally in Metaphire with spermathecal pores 0.3 apart in 7/8/9. Genital markings small near or within spermathecal and male pores. Intestinal caeca simple, smooth from 27. Spermathecal diverticula elongate. Dorsal pores from 10/11.

Distribution. Japan, Shiga-ken, Hikone (ca. $35^{\circ} 16^{\prime} \mathrm{N}$ $136^{\circ} 16^{\prime} \mathrm{E}$ ), Kaideima-cho, from 'aze' (dividing pathway) adjacently to rice paddy plots used by Shiga University.

Description. Length $30+\mathrm{mm}(\mathrm{H})$ and $45 \mathrm{~mm}$ with 70 segments $(\mathrm{P})$. Dorsum a faint brown colour with no middorsal line, clitellum darker and ventrum pale. Dorsal pores from 10/11. Setae ca. 60 per segment. Spermathecal pores ca. 0.3 circumference apart in 7/8/9. Genital markings as small discs just posterior to spermathecal pores in
$7 / 8$ and $8 / 9$ (absent from 7/8rhs on $\mathrm{H}$ ); small papillae internal to eye-like secondary male pores on 18 just median to primary male pore within small hollow construed as strictly non-superficial thereby just qualifying for Metaphire.

Internally, small stalked glands correspond to the external genital markings. Peptonephridia to 5/6, septa after this thin, $8 / 9$ present (at least ventrally) going to base of gizzard, 9/10 absent, 10/11/12 slightly thickened. Nephridia meroic forests. Spermathecae in 8 and 9 each having spherical ampulla on short duct with elongate diverticulum (inseminated). Dorsal vessel single; hearts in 10-13. Holandric, testis in sacs in 10 \& 11; seminal vesicles anteriorly in $11 \& 12$. Ovaries fan-shaped with funnels in 
13; no ovisacs in 14. Prostate racemose on long muscular ducts. Oesophagus not dilated; intestinal origin in 16 with simple, smooth caeca from 27 . Typhlosole and gut contents not recorded. Parasites not found.

\section{mtDNA COI-5P Barcode result:}

Hikone Metaphire ryunome Holotype (H) An457. BOLD Systems (www.boldsystems.org/) data for holotype tagged An457.1 (compared to sub-samples An457.2 and to paratype (P) An458.1 and An458.2 all initially tagged as "Metaphire robustus" from preliminary identification by RJB).

AACTCTATACTTTATTTTAGGAATTTGAGCCGG AATAATCGGAGCTGGGATAAGCCTACTTATCCG CATTGAACTAAGTCAACCGGGGTCTTTCCTTGG AAGAGACCAGTTATATAATACGATTGTAACAGC ACATGCATTCCTCATAATTTTCTTCTTAGTAATA CCAGTATTTATTGGGGGGTTCGGAAACTGGTTG CTACCACTAATACTAGGAACACCAGATATAGCA TTCCCCCGACTAAATAACATAAGATTTTGACTA CTCCССCСТTCCСTAATTCTCCTAGTGAGATCAG CTGCCGTAGAAAAAGGAGCAGGTACAGGTTGA ACAGTATACCCACCCCTAGCAAGAAATATAGC ACATGCGGGCCCCTCAGTAGATCTTGCAATCTT CTCACTACATTTAGCAGGTGCCTCGTCAATTTT AGGAGCTATTAATTTTATTACCACAGTGATCAA TATACGATGGTCAGGACTACGACTAGAACGAA TTCCATTATTTGTTTGAGCAGTAATAATTACTGT AGTACTACTACTATTATCACTCCCTGTACTAGC CGGTGCAATTACTATACTACTAACAGACCGAAA TCTTAACACATCCTTCTTTGATCCAGCTGGTGGT GGAGACCCAATTCTATACCAACACTTATTC

BLASTn and megaBLAST analyses:

An457.1 vs. An457.2 vs. An458.1 vs. An458.2=100\%, i.e. specimens same species.

Sequence identity of An457.1 with A. tralfamadore type is no better than $85 \%$, meaning they are different species.

Results of megaBLAST of An457.1 show that it is $99 \%$ similar to "Amynthas incongruus" voucher EF077552 from China; and is just $85 \%$ identified with "Amynthas tristriatus" voucher EF077538 from China, or with "Amynthas robustus" vouchers DQ224191 and AB542533 from Taiwan and Japan, respectively (i.e., similar to $A$. tralfamadore result).

Remarks. Although coming closest to the restricted definitions of either A. masatakae or A. robustus (Figs. $1 \&$ 2 ) the most noticeable differences are lack of markings either mid-ventrally in 18 or paired near spermathecal and/or male pores, respectively. On the basis of the morphology differing from the types of A. robustus or A. masatakae, and because the mtDNA COI barcodes differ from what workers in Japan and Taiwan label as " $A$. robustus" (including masatakae?), these Hikone specimens are thus newly named. However, it is entirely possi- ble that the COI vouchers from Japan and Taiwan represent some other valid or invalid synonyms of $A$. robustus as restored herein.

Metaphire ryunome is morphologically comparable to Kobayashi's (1937) Korean "masatakae" and to Pheretima reisuiensis Kobayashi, 1938: 139 from "Zenra-nandô" (=South Cholla) that too has spermathecal pores in $7 / 8 / 9$; however, its anterior markings are more median in intersegmental furrows, amongst many other differences such as its dorsal pores from 11/12 and setae numbering 25-60. Kobayashi (1938) figures and describes "Secondary male pore represented as a large eye-like aperture" within which the primary male porophore is found. On the basis of this, it qualifies for genus Metaphire in a new combination as $M$. reisuiensis.

Possibly both species are transitional from Amynthas Kinberg, 1867 to Metaphire Sims \& Easton, 1972, the former having superficial male pores and often complex genital markings, the latter having non-superficial male pores often with intromittent organs in "copulatory pouches" of various depths thus having less need of genital markings to adhere, attach and help co-locate superficial pores of concopulants.

\section{DiscuSSION}

The amount of basic revision required to simply put names to two specimens shows how scant our current knowledge is of earthworm species boundaries, in East Asia at least, as well as how earthworm taxonomy is in a rather chaotic state. To reiterate, no Pheretima Kinberg, 1867 s. stricto are present in Japan nor Korea, as the "default" genus for uncertainties has, for the last 40 years been Amynthas Kinberg, 1867 (see Sims \& Easton, 1972; Blakemore, 2003; 2007a, and in prep.).

As regards Amynthas micronarius, from a total of ca. 950 valid pheretimoid species from $~ 1,500$ names (Blakemore, 2007b and unpublished), approximately 125 taxa also have spermathecal pores in 5/6/7/8/9, about half are in Amynthas and, of these, Amynthas enkyokuanus (Ohfuchi, 1951: 60) from China and A. khaokhoaianus (Thai \& Samphon, 1989: 73) from Laos are known to have GMs in $17 / 18$ and $18 / 19$. Work is needed to definitively distinguish these from A. micronarius as well as any similar species having fewer spermathecae and markings that may almost certainly be confused with its numerous current synonyms. In such cases DNA barcoding helps resolution and allows detection of $A$. micronarius proper if spread further abroad.

Whilst attempting to resolve such issues, types were sought for earlier Japanese species, but syntypes remained elusive for Amynthas micronarius and for most others of Goto \& Hatai's names, despite extensive searches by 
the author (cf. Blakemore \& Ueshima, 2011; Blakemore, 2012b). Thus a neotype is explicitly erected under ICZN (1999: Art. 75) in order to objectively define this taxon's identity that has been much confused following its initial designation, accruing several synonyms and often swapping genera. The label (by Dr Hatai or his student Mr Ohfuchi?) identifies the neotype as "Ph micronaria" without details. Original type-locality was "Tokyo" whence several synonyms occur, although distribution now extends throughout Japan to Korea.

Nothing in Ohfuchi's description of his Pheretima $o b$ tusa differs substantially from A. micronarius; although it may be slightly smaller and darker on average, it is probably an amphimixic form. Ohfuchi only uses "the presence of the diverticulum" to separate it from micronarius, an inconsequential difference for parthenogenetic morphs of the same species, as is now clearly demonstrated. Other morphs were variously described as new by Ishizuka.

On the other hand, Japanese Amynthas shimaensis and A. yamizoyamensis are both now removed from Easton's (1981: 54) placement in A. micronarius, the former thought closer to A. fuscatus by Blakemore (2003: 22), while the latter's revival was mooted by Blakemore (2010a: 193). New material from Mt Fuji (above) apparently complying with the type description of A. shimaensis supports its specific status and suggests a closer link with a restored A. grossus (Goto \& Hatai, 1898).

Specimens with spermathecal pores in 6/7/8/9 and markings in 17/18 and 18/19 may sometimes key out as cosmopolitan Amynthas hupeiensis (Michaelsen, 1895) also recently collected by the author in Korea (specimens in NIBR) and in Japan, but it differs in many morphological, behavioural and ecological respects so is not considered closely related, as commented on by Ohfuchi (1937: 53) and Blakemore (2003; 2010b).

Concerning Amynthas/Metaphire placement, the division is straightforward when we have clearly defined male pores, such as in Horst's schmardae (now type-species of Duplodicodrilus Blakemore, 2008), but less easily determined for borderline cases, as here with $M$. ryunome. Then the question is simply: Are the male pores superficial? (=Amynthas), or non-superficial? $(=$ Metaphire) and, secondarily for this latter kind, are they massive and eversible (=Duplodicodrilus). It is well known that this qualifying condition for Metaphire, i.e., male pores in copulatory pouches, may have arisen more than once (e.g. Sims \& Easton, 1972: 214) but surely the precursor must always have been superficial male pores. Artefactual reversion may appear in some parthenogenetic morphs with degraded male organs, but a considered viewpoint (e.g. Blakemore 2000; 2008; 2010b) is that a non-superficial form of male pore is necessarily a development, traceable back along an evolutionary line, re- gardless of time or place, from the more basic superficial form as found in Amynthas. Thus, Sims \& Easton's (1972: 170) stated aim in separating these two genera for "more conveniently sized groups" also has some phylogenetic justification.

Does Amynthas robustus belong in Metaphire? This is currently unresolved as the state of the male pores in its type is not described in sufficient detail. Gates (1939: 476) offers no guidance as he inconsistently has male pores superficial in some specimens but invaginate in others, suggesting to me that he is referring under one heading either to parthenogenetically degraded morphs or to likely different species.

Despite megaBLAST indication, Metaphire ryunome is far removed morphologically from parthenogenetic Amynthas incongruus (Chen, 1933) that typically has spermathecal pores in 5/6/7 rather than 6/7/8, amongst other differences. This suggests that if its vouchers are one and the same species as the current one, then this is a misdiagnosis and misidentification from China since the DNA data for the present specimens are unequivocal. Similarly for the A. tralfamadore COI result that compares to several GenBank voucher names.

The challenge now is for colleagues in those places where A. robustus (Perrier) sensu stricto and its allies are thought to occur (as detailed in Blakemore, 2010b) to likewise define their taxa, both morphologically and molecularly: seeking consensus from chaos while correcting our errors sooner rather than later.

\section{REFERENCES}

Beddard, F.E. 1892. On some Perichaetidae from Japan. Zoologische Jahrbücher, Abteilung für Systematik 6:755766 [Available from: http://biostor.org/reference/14791].

Beddard, F.E. 1895. A Monograph of the Order Oligochaeta. Oxford: Clarendon Press p. 804 [Available from: http:// www.archive.org/details/monographoforder00bedd].

Beddard, F.E. 1900. A revision of the earthworm genus Amyntas. Proceedings of the Zoological Society, London 1900: 609-652 [Available from: http://www.archive.org/stream/ proceedingsofgen00scie\#page/624/mode/2up].

Bhadury, P., M.C. Austen, D.T. Bilton, P.J.D. Lambshead, A.D. Rogers and G.R. Smerdon. 2006. Exploitation of archived marine nematodes-a hot lysis DNA extraction protocol for molecular studies. Zoologica Scripta 36:93-98.

Blakemore, R.J. 2000. Tasmanian Earthworms. CD-ROM Monograph with Review of World Families. VermEcology, Canberra. 800 pp.

Blakemore, R.J. 2003. Japanese earthworms (Annelida: Oligochaeta): a review and checklist of species. Organisms, Diversity and Evolution 3(3):241-244 [Available from: Electronic Supplement 2003-11 http://www.senckenberg. 
de/odes/03-11.htm].

Blakemore, R.J. 2007a. Korean earthworm species-updated checklist. In: A Series of Searchable Texts on Earthworm Biodiversity, Ecology and Systematics from Various Regions of the World-Supplemental, CD-ROM, Yokohama National University, Japan [Available from: http://www. annelida.net/earthworm/Korean.pdf June, 2012].

Blakemore, R.J. 2007b. An updated checklist of pheretimoids. In: A Series of Searchable Texts on Earthworm Biodiversity, Ecology and Systematics from Various Regions of the World-Supplemental, CD-ROM, Yokohama National University, Japan [Available from: http://www. annelida.net/earthworm/Pheretimoids.pdf June, 2012].

Blakemore, R.J. 2008. Review of Oriental pheretimoid (Pheretima auct. : Megascolecidae) taxa with description of a new genus. [Duplodicodrilus gen. nov.]. In: T. Pavlicek \& P. Cardet (eds.), Advances in Earthworm Taxonomy III. Proceedings IOTM3. Ministry of Agriculture, Natural Resources and Environment of the Republic of Cyprus, Nicosia. pp. 23-36.

Blakemore, R.J. 2010a. Unravelling some Kinki worms (Annelida: Oligochaeta: Megadrili: Megascolecidae) Part II. Opuscula Zoologica 42(2):191-206 [Available from: http:// opuscula.elte.hu/PDF/Tomus41_2/3_\%20Blakemore_Ki niki2.pdf].

Blakemore, R.J. 2010b. Cosmopolitan Earthworms-an EcoTaxonomic Guide to the Peregrine Species of the World. (4 $4^{\text {th }}$ Edn.). VermEcology, Yokohama. 1,200 pp.

Blakemore, R.J. 2012a. Amynthas carnosus (Goto \& Hatai, 1899) redescribed on its neotype (Oligochaeta: Megadrilacea: Megascolecidae). Journal of Species Research 1(1):3543.

Blakemore, R.J. 2012b. On Opening a Box of Worms (Oligochaeta, Megascolecidae)-Historical Earthworm Specimens Transferred to Tokyo from the Saito Ho-on Kai Museum of Natural History in Sendai. Bulletin of National Museum of Nature and Science (Zoology) 38(3):1-29.

Blakemore, R.J. and R. Ueshima 2011. Catalogue of Annelida: Oligochaeta in University of Tokyo Zoology Museum (ZMUT). In: R. Ushima (Ed.), Catalogue of Invertebrate Collection Deposited in the Department of Zoology, the University Museum, the University of Tokyo (3), Phylum Annelida (Class Polychaeta, Oligochaeta, and Hirudinida). Material Reports, No. 90, 59-83 [Available from: http://umdb.um.u-tokyo.ac.jp/DDoubutu/invertebrate_ en/ oligochaeta/index.html].

Chuang, S.-C. and J.-H. Chen 2002. A new record of earthworm Amynthas masatakae (Beddard) (Megascolecidae: Oligochaeta) from Taiwan. Acta Zoologica Taiwanica 13(2):73-79 [Available from: www.zoology.lifescience. ntu.edu.tw/azt/Z-13-2/208.PDF].

Easton, E.G. 1981. Japanese earthworms: a synopsis of the Megadrile species. Bulletin of the British Museum (Natural History) Zoology 40:33-65.
Gates, G.E. 1939. On some species of Chinese earthworms with special reference to specimens collected in Szechuan by Dr. D.C. Graham. Proceedings of the United States National Museum 85:405-507 [Available from: si-dppr. si.edu/dspace/bitstream/10088/16290/USNMP-85_3040_ 1939.pdf; www.archive.org/stream/proceeding sofuni 851940unit\#page/n457/mode/2up].

Goto, S. and S. Hatai. 1898. New or imperfectly known species of earthworms. No. 1. Annotations Zoologicae Japonensis 2(3):65-78.

Goto, S. and S. Hatai. 1899. New or imperfectly known species of earthworms. No. 2. Annotations Zoologicae Japonensis 3(1):13-24.

ICZN 1999. International Code of Zoological Nomenclature ( $4^{\text {th }}$ edition). International Trust for Zoological Nomenclature, c/o Natural History Museum, London. 306 pp [Available from: http://www.iczn.org/iczn/index.jsp].

Ishizuka, K. 1999. New species of the genus Pheretima s. lat. (Annelida, Oligochaeta, Megascolecidae) from Tokyo, Japan - Part III. Species with simple intestinal caeca (I). Bulletin National Science Museum Tokyo 25(4):229-242.

Ishizuka, K. 2000a. New species of the genus Pheretima s. lat. (Annelida, Oligochaeta, Megascolecidae) from Tokyo, Japan - Part IV. The species with simple intestinal caeca (2). Bulletin National Science Museum Tokyo 26(1):1333.

Ishizuka, K. 2000b. New species of the genus Pheretima s. lat. (Annelida, Oligochaeta, Megascolecidae) from Tokyo, Japan - Part V. Species with simple intestinal caeca (3). Bulletin National Science Museum Tokyo 26(1):179-196.

Ishizuka, K. 2001. Taxonomic study of the genus Phereti$m a$ s. lat (Oligochaeta, Megascolecidae) from Japan. Bulletin of Seikei University 33(3):1-125.

Ishizuka, K., F. Shishikura and M. Imajima. 2000. Earthworms (Annelida, Oligochaeta) from the Imperial Palace, Tokyo. Memoirs of the National Science Museum Tokyo 35:179-196.

Kinberg, J.G.H. 1867. Annulata nova. Ofersigt af Kongl. Vetenskaos-Akademiens Förhandlingar, Stockholm 23(4): 97-103.

Kobayashi, S. 1937. Preliminary survey of the earthworms of Quelpart Island. Science Report of the Tohoku Imperial University (B) 11(3):333-351.

Kobayashi, S. 1938. Earthworms of Korea I. The Science Reports of the Tohoku Imperial University, Fourth Series (Biology) 13(2):89-170.

Michaelsen, W. 1900. Das Tierreich Vol. 10: Vermes, Oligochaeta. Friedländer \& Sohn, Berlin. 575 pp [Available from: www.archive.org/details/oligochaeta10mich].

Michaelsen, W. 1903. Die geographische Verbreitung der Oligochaeten. Friedländer \& Sohn, Berlin. 186 pp.

Ohfuchi, S. 1935. On some new species of earthworms from north-eastern Hondo, Japan. Science Report of Tohoku Imperial University 10(2):409-415. 
Ohfuchi, S. 1937. On the species possessing four pairs of spermathecae in the genus Pheretima, together with the variability of some external and internal characteristics. Saito Ho-On Kai Museum Research Bulletin 12:31-136.

Ohfuchi, S. 1938. New and little known forms of earthworms, Pheretima from Nippon. Research Bulletin of Saito Hoon Kai Museum 15:53-66.

Ohfuchi, S. 1956. On a collection of the terrestrial Oligochaeta obtained from the various localities in Riu-kiu Islands, together with the consideration of their geographical distribution (Part 1). Journal of Agricultural Science Tokyo Nogyo Daigaku 3:131-176.

Perrier, E. 1872. Recherches pour servir à l'histoire des lom- briciens terrestres. Nouveaux Archives du Muséum National d'Histoire Naturelle, Paris 8:5-198 [Available from: http://www.archive.org/stream/recherchespourse00perr\# page/112/mode/2up].

Sims, R.W. and E.G. Easton. 1972. A numerical revision of the earthworm genus Pheretima auct. (Megascolecidae: Oligochaeta) with the recognition of new genera and an appendix on the earthworms collected by the Royal Society North Borneo Expedition. Biological Journal of the Linnaean Society 4:169-268.

Submitted: July 20, 2012, Accepted: August 24, 2012 